\title{
Influence of Soil Properties and Composition, and Applied Hydraulic Pressures on Sample Quality of Pusan Clays
}

\author{
G. R. Konni
}

\begin{abstract}
Obtaining good quality samples from soft marine clay deposits is a challenge and it is being seen that the sample disturbance is inevitable even though lot of research has suggested using more sophisticated samplers, sampling methods, and special care being taken while handling and transportation of the samples. Hence, author doubt that apart from the above, there could also be other parameters playing critical role on the sample quality. Therefore, in the current study, sampling tube geometry is maintained same, especially angle of cutting edge and area ratio which are found to be key influencing factors and hence its impact on the current study is ignored. In the current study in order to assess the other contributing factors behind the additional sample disturbance, a special attention is given to find out other possible parameters that could also influence the sample quality. As a result of this study, it is found that the soil properties such as; silt and sand content in the soil, clay fraction, hydraulic pressure applied to penetrate the sampler, rigidity index of the soil, initial void ratio, plasticity index, and unit weight of the soil also contribute to sample disturbance. Since these properties, except hydraulic pressure, are soil inherent properties, there is always a certain minimum degree of sample disturbance associated with these soil inherent properties depending on the magnitude of these parameters. Unfortunately, the soil properties cannot be changed and thus a minimum sample disturbance is inevitable.
\end{abstract}

Index Terms-Soft marine clay, sample quality, influence of soil properties, soil composition, same sampler geometry, hydraulic pressure, inevitable.

\section{INTRODUCTION}

In the current study, a site called "Hwajeon" located along the Nakdong River, Pusan, South Korea, was proposed by Korean Government to develop both commercial and residential corridors. In general, thickness of the soft marine clays along the Nakdong River varies from $40 \mathrm{~m}$ to even $70 \mathrm{~m}$ at some locations. Huge numbers of such projects were developed in the same region where the sample quality was noticed to be poor to moderate, except a few samples, which fall under the good quality category even though using sophisticated samplers and sampling methods. Thus arriving well representing geotechnical design parameters has become a challenge for geotechnical design Engineers.

Therefore, the aim of this paper is set out to find what other possible factors (other than known common influencing factors, such as sampling methods, type of samplers, handling \& transportation, etc.) would also influence the sample quality. However, reader shall note that the estimated sample disturbance is attributed form all possible factors, as applicable, and it may be nearly impossible to quantify the factor-wise influence on sample quality. However, in the current study Author has attempted to evaluate the influence of the above said soil properties on sample quality and the results are discussed later in this paper.

In order to assess the reasons behind the inevitable sample disturbance associated with soft marine clays, author has attempted to study the influence of fundamental properties of the soil on the sample quality. Disturbed and undisturbed samples were collected from the site and all the fundamental properties of the soil such as soil composition (silt \& sand content in the soil), clay fraction $(<2 \mu \mathrm{m})$, Rigidity Index (stiffness of the soil), Initial void ratio $\left(e_{o}\right)$, Unit weight $\left(Y_{t}\right)$ and Plasticity Index $\left(I_{p}\right)$, have been estimated from both field and laboratory tests.

Sample quality has been evaluated based on the results from one dimensional consolidation tests, which were conducted on undisturbed samples retrieved from each depth from different boreholes, similarly all other required laboratory tests for this study have also been performed on samples from every depth from all the boreholes so that the correlation of the results will be appropriate and represent the nearly actual soil conditions at each depth. Whereas the soil composition (silt and sand contents and clay fraction $(<2 \mu \mathrm{m}))$ was evaluated based on the Cone penetration test (CPT) results, which have been intentionally conducted very close $(<2-3 \mathrm{~m}$ away from boreholes) to the boreholes to compare the results with other results available in this study.

The sample quality has been evaluated in accordance to the procedure illustrated in Lunne et al. (1977) and subsequently, the influence of the fundamental properties of the marine soft clays on the sample quality has been analysed and the results are discussed in the subsequent sections.

\section{GeOteChNiCAL INVESTIGATION}

In order to get all the required soil properties for the current assessment, adequate number of field and laboratory tests were planned and conducted for the study area. The performed tests and schedule is shown in Table I. 
TABLE I: SCHEDULE OF GEOTECHNICAL INVESTIGATION

\begin{tabular}{lll}
\hline \hline Testing Type & Investigation & Quantity \\
\hline & - Boreholes & 5 \\
Field tests & - Cone Penetration Tests & 5 \\
& - Field vane shear tests & 5 \\
& & \\
& - One-dimensional & 95 \\
& consolidation tests & \\
Laboratory & - Soil gradation (Sieve analysis & 95 \\
Tests & + hydrometer) & \\
& - Unit weight \&Specific gravity & 95 each \\
& - Moisture Content (Wn,LL \& & 95 \\
& PL) & \\
\hline \hline
\end{tabular}

\section{BASIC SOIL PROPERTIES From STUDY AREA}

Based on extensive field and laboratory test results from the study area, it is found that there is about $10 \mathrm{~m}$ loose sand deposit underlain by soft marine clay deposit; called as "Pusan Clay", of thickness varying from $20 \mathrm{~m}$ to $40 \mathrm{~m}$. Based on the extensive geological study for the study area, it has been found that the Pusan clay at the study area has been deposited into two major Geological Depositional Environments (K. G. Rao 2005), which are conveniently referred as "Upper clay" and "Lower clay" in the this paper.

All the required tests were carried out as per the ASTM standards and the available factual data from all the tests have been analyzed and the typical results of basic soil properties are presented in Fig. 1 including CPT data $(\mathrm{BH}-$ 9). While estimating the clay fraction in the soil, the boundary diameter of the clay particle has been defined as 2 $\mu \mathrm{m}$. Based on the yield consolidation pressure $(\sigma y)$ estimated from the one dimensional consolidation tests, Pusan clay up to top $16 \mathrm{~m}$ at the study area is slightly over consolidated. This slight over consolidation is attributed not to the change in geological settings such as erosion, but to aging effects such as secondary consolidation and chemical bonding effects (Ohtsubo et al., 1995).

\section{SAMPLER TYPES USED IN INVESTIGATION}

The main features and dimensions of the samplers used in this investigation are summarized in Table 2. The sampling tubes used in different boreholes are with minor variation in geometry. The intension behind this selection of tube geometry is that to nullify the geometry influence on the objective of current study. The angle of cutting edge is kept same for all samplers as sample quality has strong dependency on it but very less dependency on area ratio (Vuthy Horng, Hiroyuk Tanaka and Takashi Obara 2010). However, the area ratios is also maintained almost same. Therefore, the reader shall note that the influence of sampler geometry on the objective of current study shall be ignored.

\section{TABLE 2: DETAILS OF SAMPLERS USED IN THIS STUDY}

\begin{tabular}{lccllc}
\hline \hline Boreholes & BH-3 & BH-4 & BH-9 & BH-14 & BH-18 \\
\hline $\begin{array}{l}\text { Material of } \\
\text { sampler }\end{array}$ & Brass & Brass & $\begin{array}{l}\text { Stainless } \\
\text { steel }\end{array}$ & $\begin{array}{l}\text { Stainless } \\
\text { steel }\end{array}$ & $\begin{array}{l}\text { Stainless } \\
\text { steel }\end{array}$ \\
$\begin{array}{l}\text { Inner } \\
\text { dia.(mm) }\end{array}$ & 73.5 & 73.5 & 75 & 75 & 75 \\
$\begin{array}{l}\text { Outer } \\
\text { dia.(mm) }\end{array}$ & 76.3 & 76.3 & 78 & 78 & 78 \\
\hline \hline
\end{tabular}

\begin{tabular}{lccccc}
\hline \hline $\begin{array}{l}\text { Length(m) } \\
\text { Wall }\end{array}$ & 110 & 110 & 100 & 100 & 100 \\
$\begin{array}{l}\text { Thickness( } \\
\text { mm) }\end{array}$ & 1.4 & 1.4 & 1.5 & 1.5 & 1.5 \\
$\begin{array}{l}\text { Angle of } \\
\text { cutting } \\
\text { edge(deg.) }\end{array}$ & 6 & 6 & 6 & 6 & 6 \\
$\begin{array}{l}\text { Area ratio } \\
(\%)\end{array}$ & 7.76 & 7.76 & 8.16 & 8.16 & 8.16 \\
\hline \hline
\end{tabular}

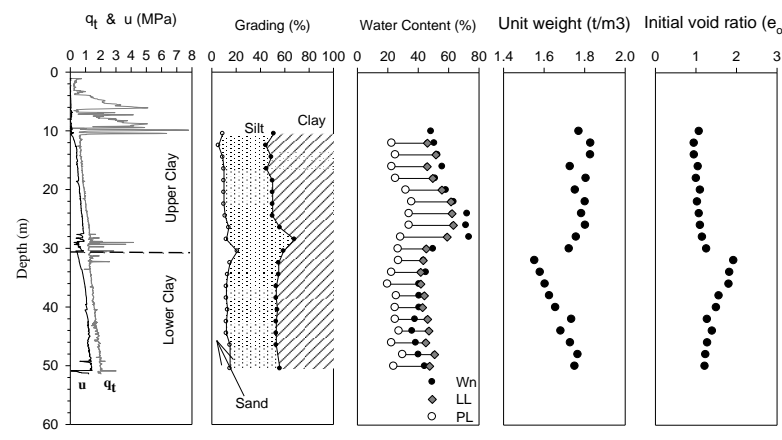

Fig. 1 Basic soil properties from study area (typical - BH-9).

\section{DRILling Methods Used}

Same drilling methods were used at all the locations to nullify its impact on the current study. Water pressures applied during the penetration of the casing, core tube associated with sediment tube (Fig 2) is used to remove the slimes $(50 \mathrm{~cm}$ below the bottom of the casing), this special core tube minimizes the sample disturbance usually associated with slime removal (Chung et al. 2004b), and then sampler was pushed to collect the undisturbed samples. Hydraulic fracture pressure of the Pusan clay at the study area is estimated (Andresen (1994)) and the applied hydraulic pressures for penetrating the sampler at required depth of sampling are maintained within the limits of hydraulic fracture pressure of the soil for shallow depths, but became unable for deeper depths as it is apparent that higher pressures are required at higher sampling depths (K. G. Rao, 2005).

\section{HANDLING, TRANSPORTATION AND STORAGE OF SAMPLES}

During sampling at the study area, all the sampled tubes were sealed with wax at both ends to prevent movement of the sample within the sampler tube, and to avoid any change in moisture content and hence the mechanical properties of the sample. Subsequently, the sampled tubes were cushioned and carefully transported to Soil testing laboratory, Dong-A University. The samples were extruded vertically from the tube with controlled hydraulic pressures and cut into desired lengths as per the different testing requirements. These cut samples were then wrapped carefully with thin plastic film and coated with two layers of wax. The wrapped samples were then stored in special boxes and preserved in a temperature controlled chamber. 

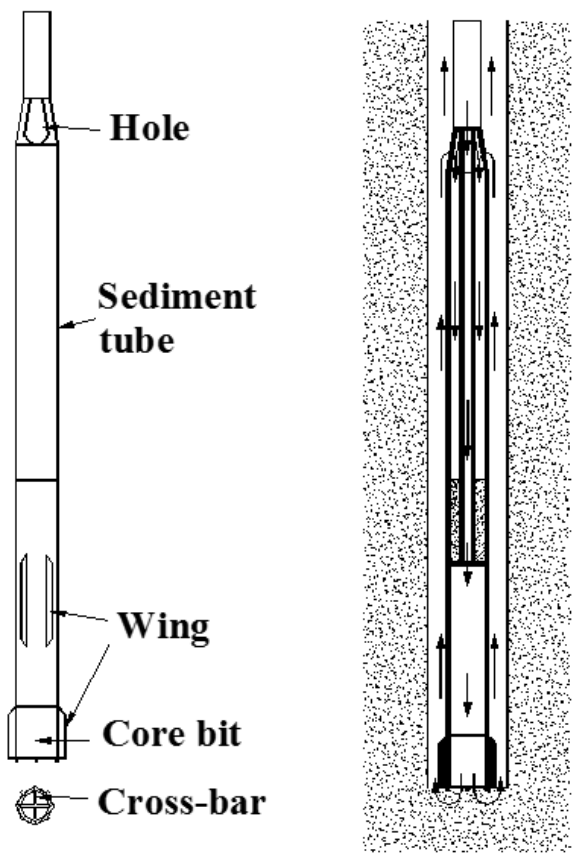

Fig. 2. Core tube with connected sediment tube

\section{EVAluATION OF SAMPle QUALITY}

The sample disturbance in the marine soft clays is inevitable despite having many advances in the sampling techniques in place, therefore it is always recommended to evaluate the sample quality and apply the appropriate corrections on soil mechanical properties to arrive well representing values for geotechnical design parameters. The degree of sample disturbance is evaluated based on the method proposed by Lunne et al. (1997) based on the results from laboratory consolidation tests carried out on undisturbed samples retrieved from different boreholes. Lunne et al. (1977) has suggested the ratio of $\Delta \mathrm{e} / \mathrm{e}_{0}$ as an indicator of sample disturbance, where $\Delta \mathrm{e}$ is the change in void ratio during the recompression process and $\mathrm{e}_{0}$ is the initial void ratio as shown in Fig. 3 which shows a typical consolidation test result from the current study area. The sample disturbance is estimated using Eq. 1 (Lunne et. Al (1997).

$$
\frac{\Delta e}{e_{0}}=\frac{e_{0}-e_{1}}{e_{0}}
$$

Alternatively, sample quality is estimated using the volumetric strain $\left(\varepsilon_{\mathrm{vo}}\right)$, equation -2 , as an indicator of sample disturbance (Andresen \& Kolstad (1979)). The procedure is illustrated in Fig 4.

$$
\varepsilon_{v 0}=\frac{\mathrm{e}_{0}-\mathrm{e}_{1}}{1+e_{0}} \times 100 \%
$$

The estimated sample disturbance using Eq. 1 for all the samples tested under laboratory one dimensional consolidation tests are presented in Fig.3 showing the variation of sample disturbance with depth for different boreholes from study area.

In general, the estimated sample disturbance would be overall combined degree of disturbance attributed from all possible influencing factors including sampling method, type of samplers, sample handling \& transportation, etc. and also other additional factors such as, soil composition, soil properties, and hydraulic pressure, etc. being suspected in current study that those may have influence on sample quality as well; But it shall be noted that it is not necessary that all the above said factors contribute to sample disturbance simultaneously, but it depends on actual conditions. In this current study, the estimated sample quality (as shown in Fig. 4) is taken as a reference degree of sample disturbance whilst evaluating the influence of the additional factors, as suspected in current study, (soil composition, soil properties and hydraulic pressure applied to penetrate the sampler) on sample quality.

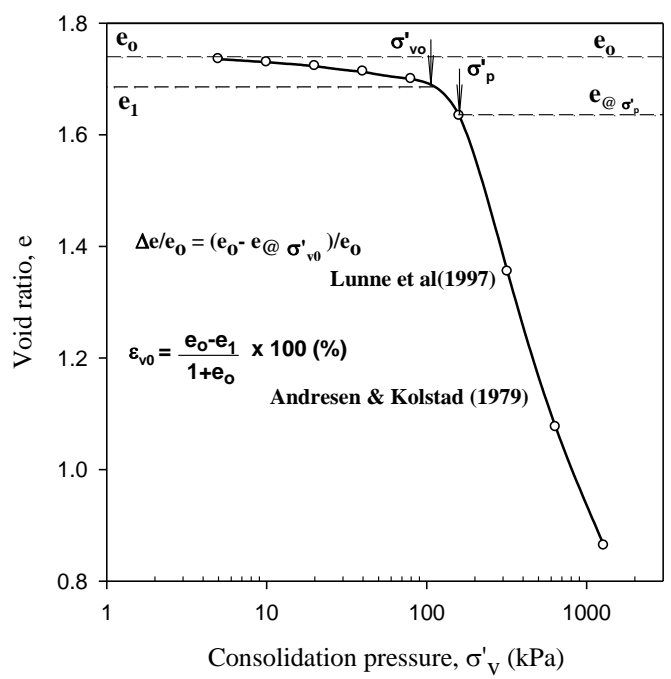

Fig. 3. A typical consolidation results showing the equations to estimate the sample disturbance.

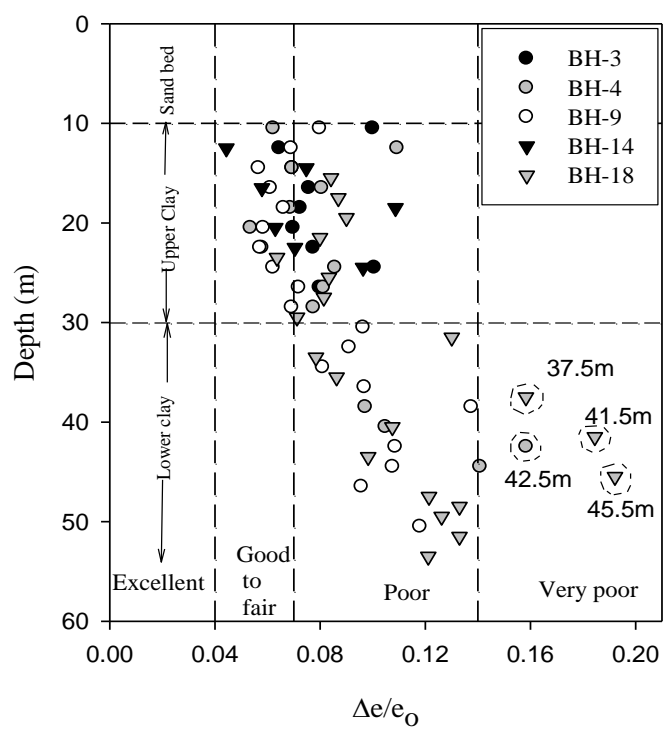

Fig. 4. Variation of sample Disturbance with depth for different boreholes from study area

\section{FACTORS INFLUENCING THE SAMPLE QUALITY}

As it can be seen from the existing relevant results from research on the sample quality of soft clays, the employed highly sophisticated sampling techniques and careful handling etc. have shown that sample disturbance could only be minimized, (Chung, Tanaka) and it seems a certain degree of disturbance is inevitable. Hence in the current 
study, in order to evaluate the hidden reasons for inevitable sample disturbance, Author has attempted to evaluate the influence of the soil properties such as soil composition (silt, sand content and clay fraction), hydraulic pressure applied to penetrate the sampler (hereafter called as sampler hydraulic pressure), initial stiffness of the soil, initial void ratio, plasticity index, and unit weight of the soil, on sample quality. The findings are discussed in detail in the sections below.

\section{A. Influence of silt and Sand Content on Sample Quality}

Silt and Sand content present in each sample has been estimated using sieve analysis and hydrometer test after completion of the consolidation test. Also silt and sand contents of Pusan clay from the study area has been estimated using results from the CPT-Pclass software (Zhang and Tumay (2003)), which generates continuous soil composition profiles using the CPT sounding raw data from all CPTs, the results from both the methods are well in agreement. The percentage of silt and sand content was estimated for all the depths where the sample disturbance data is available and eventually, the degree of estimated sample disturbance is plotted against the silt and sand contents of soil in Fig.5, including similar data from new Pusan port site in the same premises to verify the variation trend. Fig 5 (a) shows that sample quality reduces as silt content increases in the soil while Fig 5(b) shows the same with increasing sand content in the same soil. From Fig. 5 it is clear that both silt and sand contents present in the clays play a critical role in sample quality control. Furthermore, it can also be observed from Fig 5 that at the same percentage (say $10 \%$ of sand and $10 \%$ of silt), sand content in the soil has more influence on the sample quality than silt content does, which can be seen as $\Delta \mathrm{e}_{\mathrm{e}} \mathrm{e}_{0} \approx 0.075$ and 0.05 at $10 \%$ sand and $10 \%$ silt respectively, which indicates that sand has approximately $50 \%$ more influence than that of silt, which could be due to the fact that the sandy clay tends to be less cohesive and tends to be less cementitious between the soil particles than that of silty clay, and hence sandy clay is relatively easy to prone for sample disturbance. It is very interesting to note that sample quality could be good to fair and even excellent when the silt content in silty clay is less than $10 \%$ but the same is not true with sandy clay. Furthermore, it could also be inferred from the results that excellent quality samples can be obtained only when the silt and sand content are $0 \%$ in the clay provided all other influencing parameters are well controlled while sampling. However, further similar study from different sites is encouraged to arrive at more quantitative and qualitative findings.

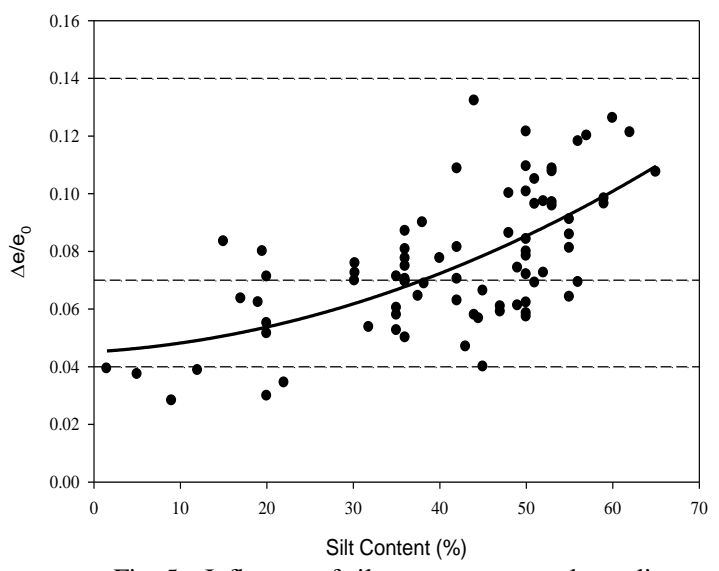

Fig. 5a. Influence of silt content on sample quality.

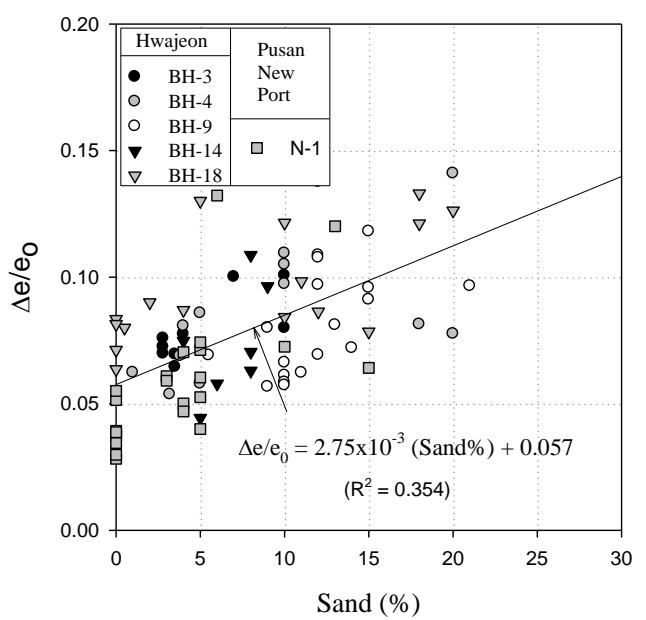

Fig. 5b. Influence of Sand content on sample quality.

\section{B. Influence of Clay fraction on Sample Quality}

Apparently, it is known that clay attributes to more cohesiveness in the soil and in turn, the more cementation between the soil particles, resulting in a strong structure of the soil. Thereby soil with high clay fraction may help to obtain relatively better quality samples provided all other influencing factors are well controlled while retrieving and handling the samples. In the current study, the clay fraction $(<2 \mu \mathrm{m})$ is estimated for all the depths corresponding to the depths where the sample disturbance is estimated and the results are plotted in the Fig 6, which shows that as the sample quality increase as the clay fraction in the soil increases. It can be seen from the same figure that when the clay fraction is roughly more than $40 \%$, the sample quality is found to be good to fair and even excellent. These findings are in the agreement with the fundamental facts stated in the beginning of this paragraph. Further study shall be encouraged to arrive more qualitative and quantitative results. 


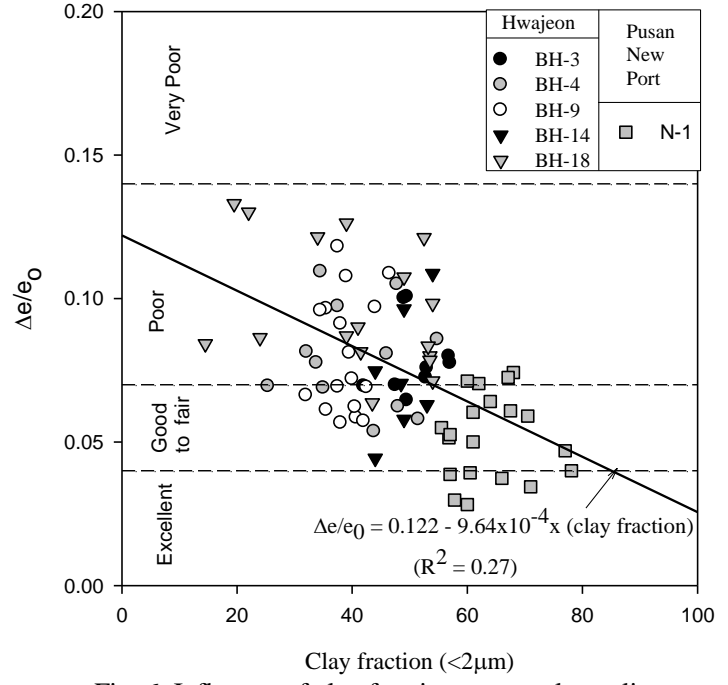

Fig. 6. Influence of clay fraction on sample quality.

\section{Influence of soil stiffness on Sample Quality}

Based on the fundamental soil mechanics, even soil stiffness would also play certain role on the sample quality. Hence in this study, an attempt has been made to evaluate the influence of the initial soil stiffness on the sample quality. The initial soil stiffness representing parameters, such as rigidity index $\left(\mathrm{I}_{\mathrm{r}}\right)$, initial void ratio $\left(\mathrm{e}_{\mathrm{o}}\right)$ and unit weight $\left(\gamma_{t}\right)$ are used to study their direct influence on the sample quality. The initial void ratio and unit weight are estimated for all the samples for which the sample disturbance is evaluated, but the rigidity index is estimated only for samples from two borehole locations (BH-3 \& BH9). The results plotted in Fig. 7. Fig. 7(a) shows the influence of the rigidity index on the sample quality, where it can be seen that sample quality reduces as the rigidity index of soil increases. Fig.7(b) shows the influence of both initial void ratio and unit weight, where it can be noticed that sample quality increases as void ratio of the soil increases, while sample quality reduces as the unit weight increases. This may be due to the fact that when soil mass is stiffer, it offers more resistance to the external pressures and thus more strains in the soil mass, which may lead to damage in the internal soil structure (bondage between soil particles), this nature of soil structure damage would be relatively lesser as soil stiffness reduces. However, author encourages further qualitative study to assess further.

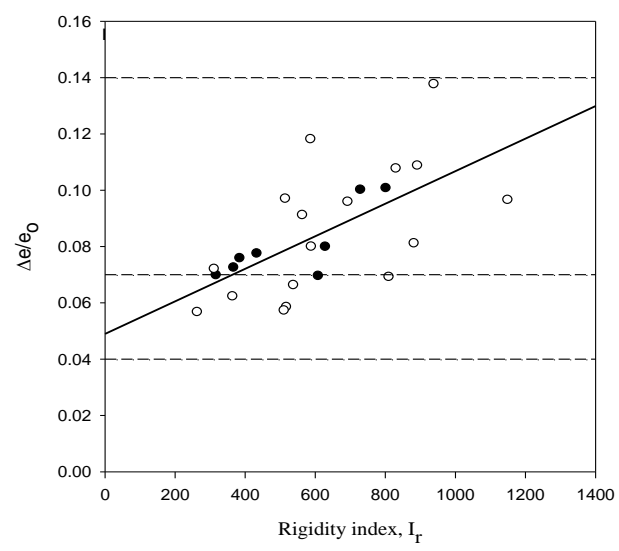

Fig. 7a. Influence of soil stiffness on sample quality.

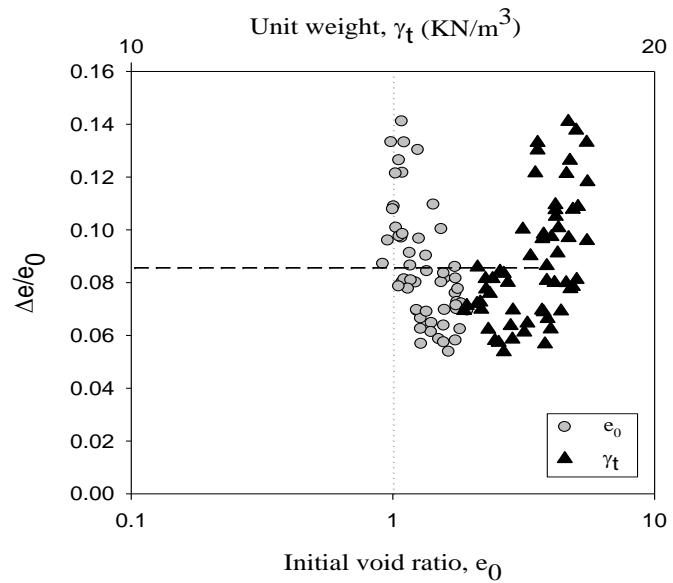

Fig. 7b. Influence of soil stiffness on sample quality.

\section{Influence of plasticity Index on Sample Quality}

The estimated volumetric strain (based on Eq. 2) and the plasticity index are plotted in the Fig. 8, which shows that sample quality increases as the plasticity Index of soil increases; which means that plasticity property of the clay helps to obtain the better quality samples, provided all other influencing factors are well controlled.

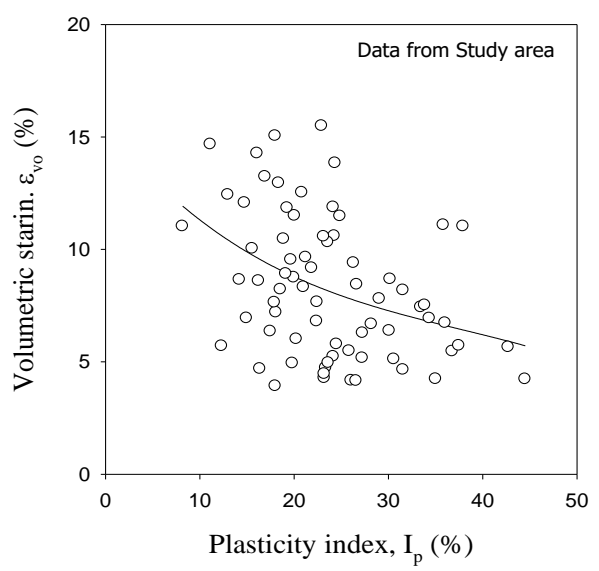

Fig. 8. Influence of plasticity index on sample.

\section{E. Influence of Applied Hydraulic Pressure on Sample Quality}

According to ASTM stated that a faster rate of penetration of sampler would reduce the possible mobilization of frictional resistance between the soil and sampler, and in turn it helps to reduce the sample disturbance. However, it is obvious that faster penetration requires higher hydraulic pressures, which may result in higher sample disturbance. However, the influence of the hydraulic pressure applied to penetrate the sampler (hereafter called as sampler hydraulic pressure) on sample quality is studied in a great extent in this paper.

In the current study, it was thought that sampler hydraulic pressure required at different sampling depths would also play critical role on sample quality as this pressure can cause damage to the soil structure/bondage between the soil particles, especially when sampler hydraulic pressure exceeds the soil fracture pressure (Andersen, 1994). In order to quantify its influence on sample quality, sampler hydraulic pressures are recorded at every depth of sampling 
and plotted against the sample disturbance estimated as shown in Fig. 9 where it can be apparently seen that as the sampler hydraulic pressure increases the sample quality decreases. As could be seen from Fig. 9 that when the applied hydraulic pressure is $\leq 20 \mathrm{~kg} / \mathrm{cm} 2$, the sample quality is relatively good to fair, except a few samples falling under poor quality, which may be due to the fact that the presence of relatively higher sand content as observed in those samples, which might be the one of the reasons to cause this additional sample disturbance and lead to the poor sample quality.

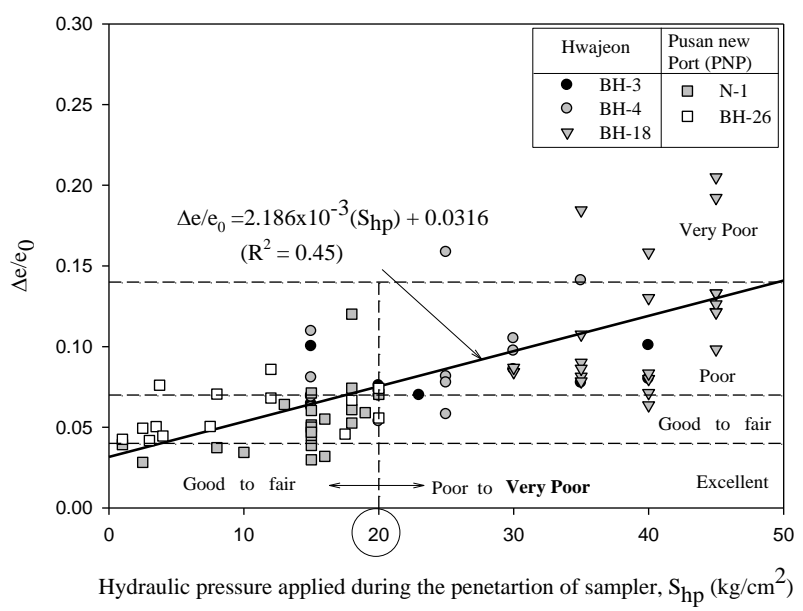

Fig. 9. Influence of hydraulic pressure applied during penetration of sampler on sample quality.

\section{CONClusions}

From this study carried out based on the comprehensive geotechnical investigation conducted for the study area, the following conclusions can be drawn:

a. It is strongly believed that sample quality not only depend on the sampler geometry but also depend on soil properties, soil composition and sampler hydraulic pressure. Otherwise in the current study, the sample quality would have been remained same.

b. Since the soil properties and soil composition are inherent properties and cannot be changed, a degree of sample disturbance attributed from these cannot be minimized. This could be the reason for not being able to obtain $0 \%$ disturbance samples, even though very sophisticated sampling techniques are used and special care is taken during transportation and handling.

c. Clay fraction in soil exceeding $40 \%$ shows the possibilities of obtaining the good quality samples provided the other influencing factors are well controlled.

d. It is observed that the sampler hydraulic pressure of $\leq 20 \mathrm{~kg} / \mathrm{cm} 2$ helps to obtain the good quality samples.

e. Sand content in soil has more influence than silt content in soil. Silt content in soil up to approximately $15 \%$ has no significant influence on the sample quality.

f. Since certain degree of Sample disturbance is inevitable, it is recommended to evaluate sample quality and appropriate corrections shall be applied on mechanical properties so as to arrive at well representing values for geotechnical design parameters.

g. Author recommends to encourage further similar studies on different clays so as to quantify the actual degree of disturbance being attributed by these soil properties and soil composition so that one can appropriately take care while arriving at geotechnical design parameters for foundation design.

\section{REFERENCES}

[1] Andresen, A., and Kolstad, P. 1979. The NGI $54 \mathrm{~mm}$ sampler for undisturbed sampling of clays and representative sampling of coarser materials. In Proceedings of the International Symposium of Soil Sampling, Singapore, 28 July 1979, Japanese Society of Soil Mechanics and Foundation Engineering. pp. 13-21.

[2] Andresen, K. H. Rawlings, C. G, Lunne, T. A., and Trond, H. (1994), Estimation of hydraulic fracture pressure in clay, Canadian Geotechnical Journal; Vol. 31, PP.817 -828

[3] Chung, S.G., Kwag, J.M., Giao, P.H., Back, S.H., Prasad, K.N., 2004 A study of soil disturbance of Pusan clays with reference to drilling, sampling and extruding. Geotechnique 54 (1), 61-65.

[4] K.G. Rao, 2005, "Comprehensive experimental investigation for Characterization of Pusan Clays in the west coast of Nakdong River estuary”, Ph.D Thesis, Dong-A University, Pusan, South Korea

[5] Lunne, T., Berre, T., and Strandvik, S. 1997. Sample disturbance effects in soft low plastic Norwegian clay. In Proceedings of the Conference on Recent Developments in Soil and Pavement Mechanics, Rio de Janeiro, Brazil, 25-27 June 1997. A.A. Balkema, Rotterdam. pp. 81-102.

[6] Ohtsubo, M. et. al (1995) "Depositional and post-depositional geochemistry, and its correlation with the geotechnical properties of marine clays in Ariake bay, Japan, " Geotechnique, Vol. 45, No. 3, PP. 509-523.

[7] ISSMFE (1988) "Cone Penetration Test (CPT): International Reference test procedure," Proc. Of the 1st Int. symposium on penetration testing, Vol. 1 PP. 27-52.

[8] Vuthy Horng, Hiroyuki Tanaka, and Takashi Obara. 2010. Effect of sampling tube geometry on soft clayey sample quality evaluated by non-destructive methods. Journal of soils and foundations, Vol. 50, No.1, PP 93-107

[9] Zhang, Z. \& Tumay, M.T "The Nontraditional Approaches in Soil Classification Derived from the Cone Penetration Test" ASCE Special Publication No. 121, Probabilistic Site Characterization at the National Geotechnical Experimentation sites, February 2003, pp. 101.

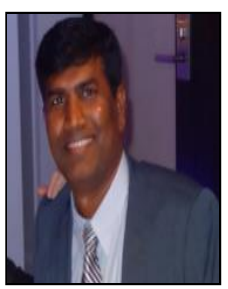

Dr. Konni. G. R. was born in Nandigam, Andhra pradesh, India, in 1976. He has received B.tech degree in Civil Engineering from University of Jawaharlal Nehru Technological (JNTU), kakinad, India in 1999, and M.Tech in geotechnical Engineeirng from Jadavpur University, Kolkata, India in 2002 and Ph.D in geotechnical Engineeirng from Dong-A Univesity, Pusan, South Korea, in May 2005.

Immediately after M. Tech, joined the department of Civil Engineering, Sri Venkateswara University, India as adjunct faculty for short period in 2002. After Ph.D program, joined as a full-time researcher cum faculty in Department of Civil Engineering, Dong-A University, South Korea, worked till 2006. Then, in December 2006, he has joined in Dong-A Geological Engineering India Pvt. Ltd as a Technical Engineering Manager for projects in power Sector, mainly hydropower projects and worked for 5 years in India. In December 2011, Joined as Technical Specialist in Petrofac International Ltd., Dubai, UAE, mainly worked for Oil \& Gas Industry, for projects across the globe, still working with the same organization. During his industrial Journey, he has achieved different achievements like "EVE-award", good saving by foundation optimization in multiple projects, etc.

$\mathrm{He}$ has contributed research works in different Journals, International conferences, research Institutes, and Society of Petroleum Engineering. His current research interests include site characterization, ground improvement, sample quality, field testing, foundation design, liquefaction analysis, land reclamation, Pile load testing and optimization, land development and soil reinforcement with geo-synthetics.

Dr. Konni is life member of Indian Geotechnical Society and Rock-works, India. 
His main goal is to work as a faculty in a good University where there is potential for research works. 